\title{
SIMPLE MODEL FOR LOW INTENSITY TURBULENCE EFFECTS ON THE VAPORIZATION OF LIQUID SINGLE DROPLETS IN FORCED CONVECTIVE CONDITIONS
}

\section{Maher M. Abou Al-Sood}

Mechanical Engineering Department, Faculty of Engineering, Assiut

University, Assiut (71516), EGYPT

Email: $\underline{m \text { aboualsood@hotmail.com }}$

(Received December 5, 2010 Accepted January 12, 2011)

This paper presents a semi-analytical analysis for modeling effects of moderate turbulence flows on the vaporization of an isolated fuel droplet at ambient room temperature and atmospheric pressure conditions. The turbulent Nusselt and Sherwood numbers used in this model are purely empirical. Two different hydrocarbon fuels were tested, i.e. n-heptane, and n-decane each has an initial diameter of $1.5 \mathrm{~mm}$. The droplet Reynolds number, Red, is changed in the range (60-500), and turbulence intensity varied between $0 \%$ and $11 \%$. The major findings of this study showed that the droplet's vaporization rate, which is deduced from the steady-state linear variation of the droplet squared diameter, increases with increasing turbulence intensity. Also, the results from using several liquid fuels, i.e. n-hexane, n-heptane, n-octane and n-decane, show that the vaporization Damköhler number, Dav, is correlated to nondimensional turbulence evaporation rate, $K / K L$, by an exponential relation. Also, the applicability of this correlation at high Reynolds numbers has been studied.

KEYWORDS: Droplet, Vaporization, Modeling, Turbulence,

Damköhler number

\section{NOMENCLATURE}

$B_{T} \quad$ Spalding heat transfer number

$B_{M} \quad$ Spalding mass transfer number

$C_{p} \quad$ Constant pressure specific heat $(\mathrm{kJ} / \mathrm{kgK})$

$D_{a v} \quad$ Evaporation Damköhler number

I Turbulence intensity (\%)

$K \quad$ Evaporation rate $\left(\mathrm{m}^{2} / \mathrm{s}\right)$

$k \quad$ Thermal conductivity (W/m.K)

$L \quad$ Latent heat of vaporization $(\mathrm{J} / \mathrm{kg})$

$L_{e} \quad$ Integral length scale (m)

$l_{m} \quad$ Mixing length scale $(\mathrm{m})$

$M \quad$ Molecular weight ( $\mathrm{kg} / \mathrm{k}$ mole)

$m$ mass

$\mathrm{Nu} \quad$ Nusselt number

$p \quad$ Pressure $(\mathrm{Pa})$ $p_{f s} \quad$ Partial pressure of fuel vapor (Pa)

$\dot{Q} \quad$ Rate of heat transfer (W)

Re Reynolds number

$R e_{T}$ Turbulent Reynolds number

$r$ Instantaneous droplet radius (m)

$r_{o} \quad$ Initial droplet radius (m)

Sh Sherwood number

$T_{b} \quad$ Normal boiling temperature (K)

$T_{c} \quad$ Critical temperature $(\mathrm{K})$

$T_{d} \quad$ Droplet temperature $(\mathrm{K})$

$T_{s} \quad$ Surface temperature $(\mathrm{K})$

$U$ Mean stream velocity $(\mathrm{m} / \mathrm{s})$

$u$ ' Velocity fluctuation $(\mathrm{m} / \mathrm{s})$

$V_{r} \quad$ Blowing velocity of vapor $(\mathrm{m} / \mathrm{s})$

$X_{F} \quad$ Mole fraction of fuel vapor 


\begin{tabular}{|llll|}
\hline \multicolumn{2}{|l|}{$y_{F}$} & Mass fraction of fuel vapor & \multicolumn{2}{l|}{ Subscripts } \\
Greek & $a$ & Air \\
$\gamma$ & Surface tension $(\mathrm{N} / \mathrm{m})$ & $d$ & droplet \\
$\tau_{t}$ & Turbulence integral time scale $(\mathrm{s})$ & evap & evaporation \\
$\tau_{v}$ & Vaporization time scale $(\mathrm{s})$ & $f$ & fuel \\
$\delta_{M}$ & Vapor film thickness $(\mathrm{m})$ & $g$ & gas (mixture of air and fuel vapor \\
$\mathcal{E}$ & Turbulence dissipation rate $\left(\mathrm{m}^{2} / \mathrm{s}^{3}\right)$ & & at film conditions) \\
$\mu$ & Viscosity $(\mathrm{Pa} . \mathrm{s})$ & $s$ & radiation \\
$v$ & Kinematic viscosity $\left(\mathrm{m}^{2} / \mathrm{s}\right)$ & $v$ & surface \\
$\rho$ & Density $\left(\mathrm{kg} / \mathrm{m}^{3}\right)$ & $\infty$ & free stream \\
\hline
\end{tabular}

\section{INTRODUCTION}

The evaporation of fuel droplets is fundamentally and practically important for many engineering systems powered by liquid fuels such as internal combustion engines. In these systems, fuel is injected into combustion chamber as a spray or jet. This spray consists of a liquid core and dispersed flow region that begins right after the jet exit and consists of multiphase mixing layer where the liquid core is present followed by a dilute flow that involves round and small drops with a small liquid volume fraction. This implies that the drops collisions and effect of surrounding drops are improbable. This support the classical picture of atomization within dense spray, i.e. primary break-up into ligaments and large drops at the surface of the liquid core followed by secondary break-up into smaller round drops with negligible effect of collision. Those small round drops evaporate due to the surrounding atmosphere forming a combustible mixture that ignites once appropriate conditions are achieved. The evaporation process controls the combustion process that eventually controls the performance of engine, pollution and design of combustion chamber

Vaporization of single droplets is necessary in spray modeling. Detailed studying of the vaporization of a single liquid fuel droplet is based on solving NavierStokes equations and provides useful information on the evaporation history and parameters that affect this process. These studies cannot be in practical use for complex spray models because of time consuming. However, it can be used to develop such correlations for heat and mass transfer to develop simple models simulating the evaporation process in spray modelling.

The problem of liquid droplet evaporating in free and forced convective flows received a great attention in the last century. This resulted in the establishment of wellaccepted correlations for the heat and mass transport rates from a liquid droplet. Much of the credits of this great progress go to the pioneering research work undertaken by Frössling [1] in the late nineteen thirty's and, Ranz and Marchall [2] in the late nineteen fifty's. However, these correlations are applicable only to a droplet evaporating in a laminar convective flow. On the contrary, the evaporation process of a liquid droplet in turbulent flow conditions received a little interest, and consequently it is still less understood. Early and recent experimental, theoretical and numerical studies on turbulence effects on the transport rates from spheres and liquid droplets are reviewed in [3] and, therefore, are not discussed in this article. The review carried out 
in [3] showed that most of the available published works on turbulence effects on droplet vaporization in forced convective flows [4-8] or in zero-mean velocity turbulent flows [9-10] are experimental. Some numerical studies are available in the open literature [11-16]. The main conclusion is that turbulence enhances the evaporation process of droplets. The main objective of the present study is to propose a simple model for predicting the turbulent vaporization rate of a liquid fuel droplet subjected to moderate turbulence convective flows at ambient room temperature and atmospheric pressure. This simple model is presented below along with some sample results.

\section{TURBULENT EVAPORATION MODEL}

The present model is an extension to the model developed in [17]. The model developed in [17] is capable of predicting the vaporization rate of a liquid droplet in stagnant or laminar convective flows. The main novelty of the present model is that the laminar Nusselt and Sherwood numbers employed in [17] are replaced by turbulent ones. Hence, the applicability of the present model extends to predict also the turbulent vaporization rate of a liquid droplet exposed to forced convective flows with moderate turbulence. The present model is based on the following assumptions: (i) the droplet is a one component hydrocarbon with no chemical activity with the surrounding gas; (ii) the droplet shape remains spherical because the Weber number ( $\left.W e=\rho U_{\infty}^{2} d / \gamma_{d}\right)$ is assumed much less than unity; (iii) the gas phase is isotropic turbulent with predefined turbulence intensity; (iv) second order effects such as Dafour effect (energy flux due to mass concentration) and Sort effect (mass diffusion due to temperature) are not considered; (v) the solubility of the ambient gas into liquid phase is generally considered at high pressure and, therefore it is neglected at this study as the pressure is kept atmospheric; (vi) radiation is negligible, as it is very small compared to other energy terms of equation (1). The later assumption is accepted at low ambient temperature [14-16] such as the case in the present investigation., the energy balance at the droplet's surface may be expressed as:

$$
\dot{Q}=m_{d} c_{p l} \frac{d T_{s}}{d t}+\dot{m}_{\text {evap }} L,
$$

where $\dot{Q}_{\text {is }}$ the rate of heat transfer from gas to liquid, Ts is the droplet temperature, $m_{d}=(\pi / 6) d^{3} \rho_{l}$ is the droplet mass, cpl, $\rho 1$ are specific heat and density of liquid droplet, respectively, $\dot{m}_{\text {evap }}$ is the rate of liquid mass evaporated, and $\mathrm{L}$ is the latent heat of vaporization. The heat transfer by radiation is neglected, as stated above. The heat transfer from gas phase to liquid phase can be expressed as:

$$
\dot{Q}=\pi d k_{g}\left(T_{\infty}-T_{s}\right) N u_{d}
$$

where $\mathrm{kg}$ is the gas thermal conductivity, $\mathrm{Nu}$ is Nusselt number, and $\mathrm{T} \infty$ is the free stream temperature. The rate of mass transfer from the droplet $\dot{m}_{\text {evap }}$ appearing in equation (1) is expressed as $[17,18]$ :

$$
\dot{m}_{\text {evap }}=\pi d \rho_{g} D_{g} B_{M} S h_{d}
$$


where $\rho g$ and Dg are density and diffusion coefficient of gas mixture (fuel vapor and air) at film conditions.

In the present model, the flow surrounding the liquid droplet is turbulent and hence the turbulent correlation for the Sherwood and Nusselt numbers were proposed. These correlations, which are valid for both laminar and turbulent flow conditions, are expressed as [6]:

$$
\begin{aligned}
& N u_{d}\left(1+B_{T}\right)^{0.7}=2+0.58 \operatorname{Re}_{g}^{1 / 2} \operatorname{Pr}_{g}^{1 / 3}\left(1+0.07 I^{0.843}\right) \\
& S h_{d}\left(1+B_{M}\right)^{0.7}=2+0.52 \operatorname{Re}_{g}^{1 / 2} S c_{g}^{1 / 3}\left(1+0.07 I^{0.843}\right)
\end{aligned}
$$

These correlations were valid for the following conditions: $50<\operatorname{Reg}<1500,0$ $\%<\mathrm{I}<11 \%$, where $\mathrm{I}$ is the turbulence intensity taken as $\mathrm{u} / \mathrm{U} \times 100$, where $\mathrm{u}$ ' and $\mathrm{U}$ are the fluctuation and mean velocity, respectively. Schmidt, Lewis, Prandtl and Reynolds numbers were calculated as: $S c_{g}=\mu_{g} /\left(\rho_{g} D_{g}\right), \quad L e_{g}=k_{g} /\left(\rho_{g} c_{P_{g}} D_{g}\right)$, $\operatorname{Pr}_{g}=S c_{g} / L e_{g}$, and $\operatorname{Re}_{g}=d \rho_{\infty} U / \mu_{g}$, respectively. While, BT and BM appearing in equations (3) through (5) are the Spalding heat and mass transfer numbers given, respectively, as [17]:

$$
\begin{aligned}
& B_{T}=c_{p g}\left(T_{\infty}-T_{s}\right) / L \\
& B_{M}=\left(y_{f S}-y_{f \infty}\right) /\left(1-y_{f s}\right),
\end{aligned}
$$

Where yfs is the mass fuel vapor fraction at droplet surface and can be calculated as $y_{f s}=p_{f s}\left(T_{s}\right) M_{f} /\left(p_{f s} M_{f}+\left(p-p_{f s}\right) M_{g}\right)$. Here pfs is the fuel vapor saturated pressure which is evaluated using Antoine correlation mentioned in Poling et al. [19].

$$
\ln p_{f s}=A-\frac{B}{T_{s}+c},
$$

Where $\mathrm{A}, \mathrm{B}$ and $\mathrm{C}$ are constants depending on the fluid type and are taken from [19]. The viscosity of air and vapor mixture is calculated according to Wilke approximation mentioned in Poling et al. [19].

$$
\mu_{g}=\left(\frac{\left(1-y_{f s}\right) \mu_{a}}{\left(1-y_{f s}\right)+y_{f s} \phi_{a v}}\right)+\left(\frac{y_{f s} \mu_{v}}{y_{f s}+\left(1-y_{f s}\right) \phi_{v a}}\right)
$$

where:

$$
\left.\begin{array}{l}
\phi_{a v}=\frac{\left[1+\left(\frac{\mu_{a}}{\mu_{v}}\right)^{1 / 2}\left(\frac{M_{v}}{M_{a}}\right)^{1 / 4}\right]^{2}}{\left[8\left(2+\frac{M_{a}}{M_{v}}\right)\right]^{1 / 2}}, \\
\phi_{v a}=\left(\frac{\mu_{v} M_{a}}{\mu_{a} M_{v}}\right) \phi_{a v}
\end{array}\right\}
$$

The latent heat of fuel at surface temperature, Ts, is expressed as: 


$$
L\left(T_{s}\right)=L\left(T_{b}\right)\left[\frac{T_{c}-T_{s}}{T_{c}-T_{b}}\right]^{0.38}
$$

where $\mathrm{L}(\mathrm{Tb})$ is the fuel latent heat of vaporization evaluated at normal boiling temperature $\mathrm{Tb}$, and $\mathrm{Tc}$ is the critical temperature.

Finally, all the thermophysical properties of liquid and vapor are calculated from references [19, 20], and the vapor-air mixture properties (denoted with subscript "g") are evaluated using the reference temperature and fuel concentration, i.e. equations $(12,13)$, where $\mathrm{Ar}=1 / 3$ refers to the widely used film conditions.

$$
\begin{aligned}
& T_{r}=T_{s}+A_{r}\left(T_{\infty}-T_{s}\right) \\
& y_{f r}=y_{f s}+A_{r}\left(y_{f \infty}-y_{f s}\right)
\end{aligned}
$$

\section{SOLUTION PROCEDURE}

Calculations of droplet temperature and instantaneous droplet diameter are based on iterative method proposed by Chen et Lefebvre [21] for the model presented in Eqs. (113). Starting from $t=0, d=d_{o}$ and $T_{s}=T_{s o}$, and time interval $\Delta t$. The heating up period is terminated if the rate of heat penetrating the droplet is zero or negative and all the heat transfer from gas is used to evaporate fuel. The evaporation process is terminated, also, when the ratio between the droplet diameter and initial diameter becomes less than 0.3 , which means that $97.3 \%$ of the droplet is evaporated.

\section{RESULTS AND DISSCUSIONS}

The evaporation of droplets of $n$-heptane and $n$-decane subjected to turbulent air flow is considered. The initial droplet temperature is $253 \mathrm{~K}$ and its initial diameter is 1.5 $\mathrm{mm}$. The turbulent air around the droplet is at room temperature and atmospheric pressure $(300 \mathrm{~K}, 1 \mathrm{~atm})$, turbulence intensity changes up to $11 \%$ and mean flow velocities were changed between $(0.6-5 \mathrm{~m} / \mathrm{s})$.

Figure 1 shows the time history of normalized square droplet diameter $\left(d / d_{0}\right)^{2}$ for of $n$-heptane at stagnant, laminar, and at different turbulence intensities. Here a droplet life time is ended when $97.3 \%$ of the droplet mass has been evaporated. It is clear that the droplet life time decreases with increasing turbulence intensity. This figure shows that the $d^{2}$-law $\left(d^{2}=d_{o}^{2}-K t^{2}\right)$ holds for all cases with different slopes (evaporation rate). The evaporation rate increases with increasing turbulence intensity. This happens as turbulence is capable to transmit large shear stresses and to diffuse heat and matter more rapidly than corresponding laminar flow. The overall effect of turbulence is equivalent to increasing greatly the effective coefficients of viscosity, heat conductivity and diffusivity. Also, the same trend is obtained for $n$-decane with a long droplet life time as shown in Figure 2. The effect of droplet temperature on droplet density is negligible and the swelling effect is not noticed in both figures. This swelling may not be a serious problem in the injection cases in cold ambient gases, but becomes important in high temperature taking place in the fuel injection in diesel engine. 
Droplet turbulent vaporization rate of $n$-heptane and $n$-decane normalized by stagnant evaporation rate is displayed in Figure 3. This Figure shows that the prediction of the present study is slightly higher than that of the only experimental data available in the open literature of $\mathrm{Wu}$ et al. [7] but the trends are almost the same. This might be due to the handicap of the heat and mass transfer numbers employed in this model as discussed in $[14,16]$.

Variations of surface temperature with time for $n$-heptane and $n$-decane are displayed in Figure 4. This figure shows that the surface temperature for $n$-decane (low volatility) is higher than that of $n$-heptane (high volatility). This stems from the fact that wet bulb temperature of $n$-decane in air is higher than that of $n$-heptane in air.

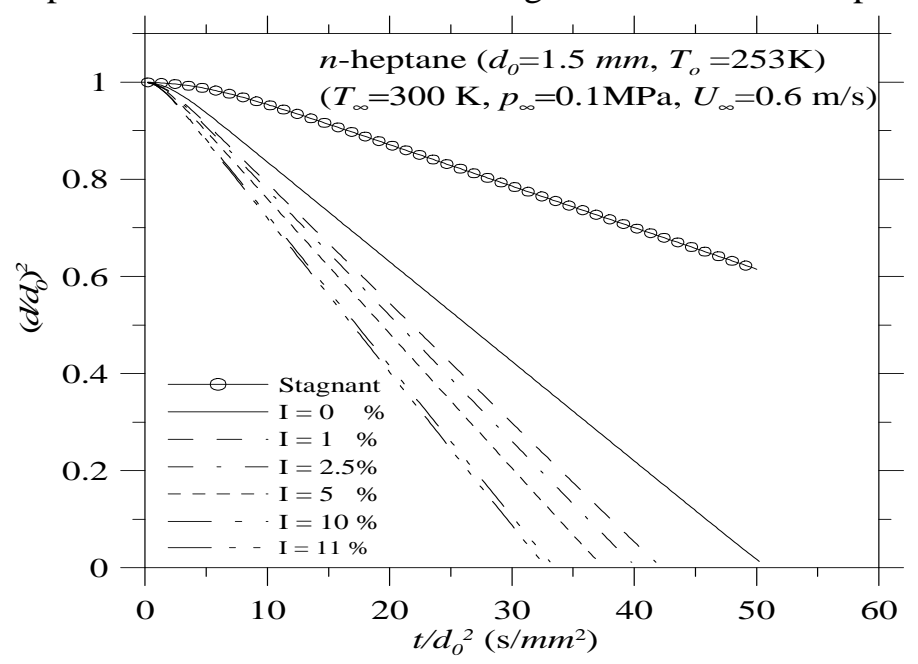

Figure 1 Time history of normalized diameter of n-heptane at stagnant, laminar and turbulent conditions

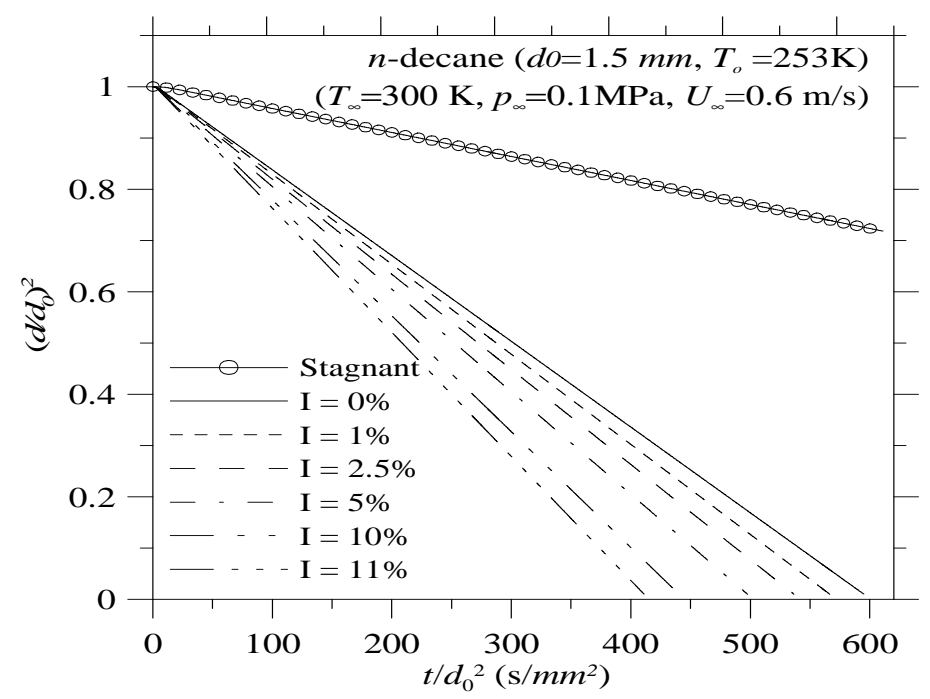

Figure 2 Time history of normalized diameter of $n$-decane at stagnant, laminar and turbulent conditions 


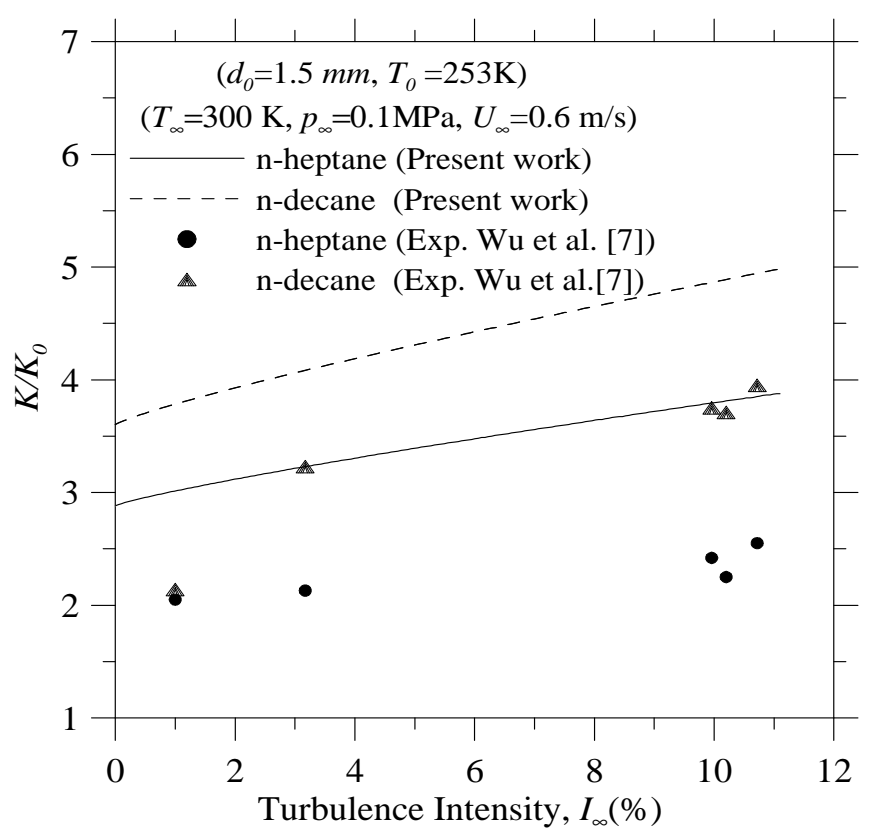

Figure 3 Comparison of normalized turbulent evaporation for $n$-heptane and $n$-decane with experimental data

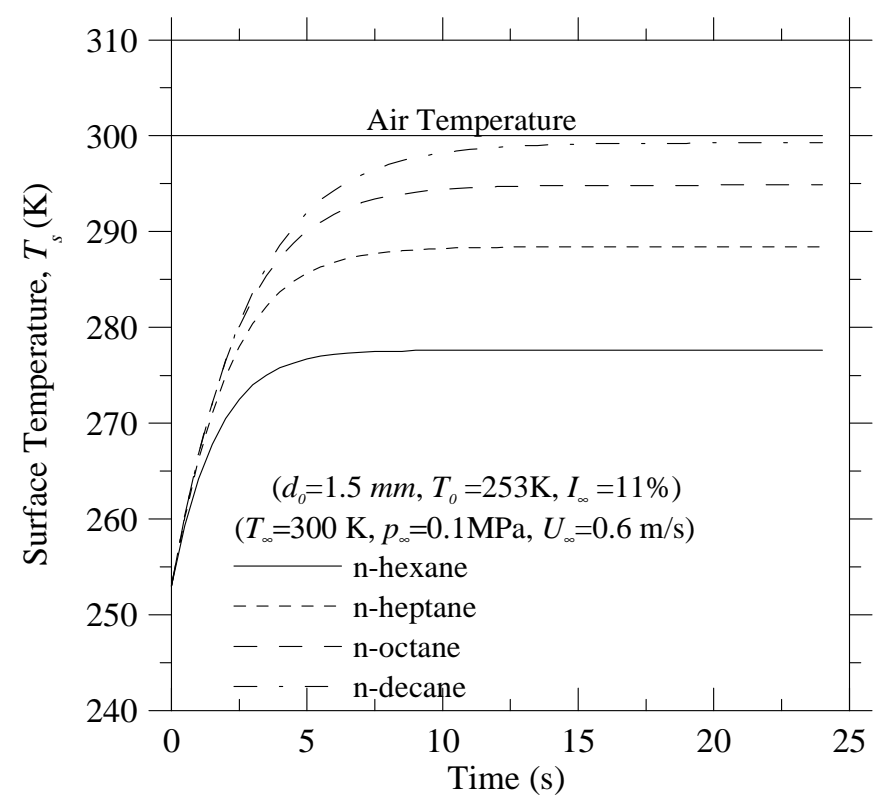

Figure 4 Surface temperatures of $n$-heptane and $n$-decane droplets

Gökalp et al. [4] proposed a correlation, based on fitting their experimental data, to show the effect of turbulence alone on mass transfer rate normalized by its stagnant case as $K_{T}^{\prime}=\left(K-K_{L)} / K_{0}=C_{1} I_{\infty}\right.$. This correlation has been checked in the 
present study and it is found that this correlation does not fit the present data well and the power law correlation fits the present data very well. This power law correlation can be represented as $K_{T}^{\prime}=C_{1} I^{0.84}$. Figure 5 represents the variation of normalized turbulent evaporation rate with turbulence intensity at different mean velocities for $n$ heptane. The value of normalized turbulent evaporation rate increases with mean velocity and the same trends are noticed also for less volatile fuel (i.e. $n$-decane). In reference [4], authors proposed a linear correlation between the normalized turbulent evaporation rate and turbulence Reynolds number $\left(\operatorname{Re}_{T}=u d / v\right)$. This correlation is represented as $K_{T}^{\prime}=C_{2} \operatorname{Re}_{T}$. Again, this correlation is checked with the current results and a power correlation, i.e. $K_{T}^{\prime}==C_{2} \mathrm{Re}_{T}^{0.84}$, seems to represent present data, illustrated in Figure 6, very well. It seems that the discrepancies between the present data and Gökalp et al. [4] data might be due to the insufficient data presented in [4] that cannot give an accurate trend. The constants $C_{1}$ and $C_{2}$ are different from fuel to fuel and depend on mean velocity. Variations of $C_{1}$ and $C_{2}$ with mean velocity for $n$-heptane and $n$-decane are illustrated in Figures 7 and 8 , respectively. These figures show that the effect of mean velocity on turbulent evaporation is a little more pronounced for the less volatile fuels.

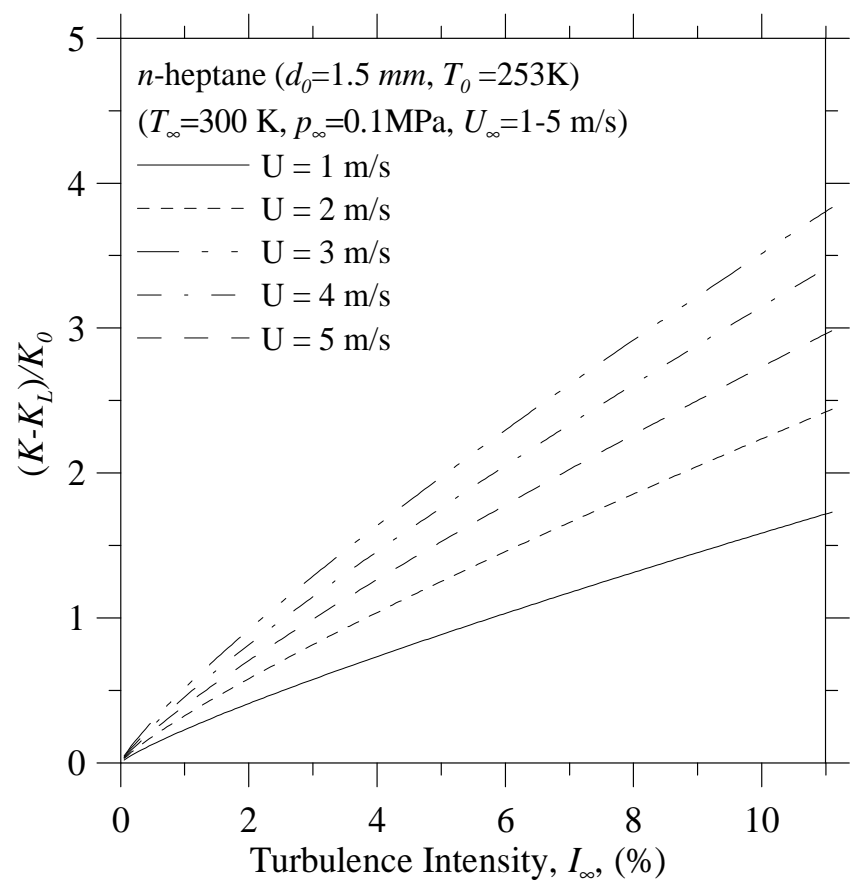

Figure 5 Effect of turbulence intensity on vaporization of n-heptane at different mean velocities 


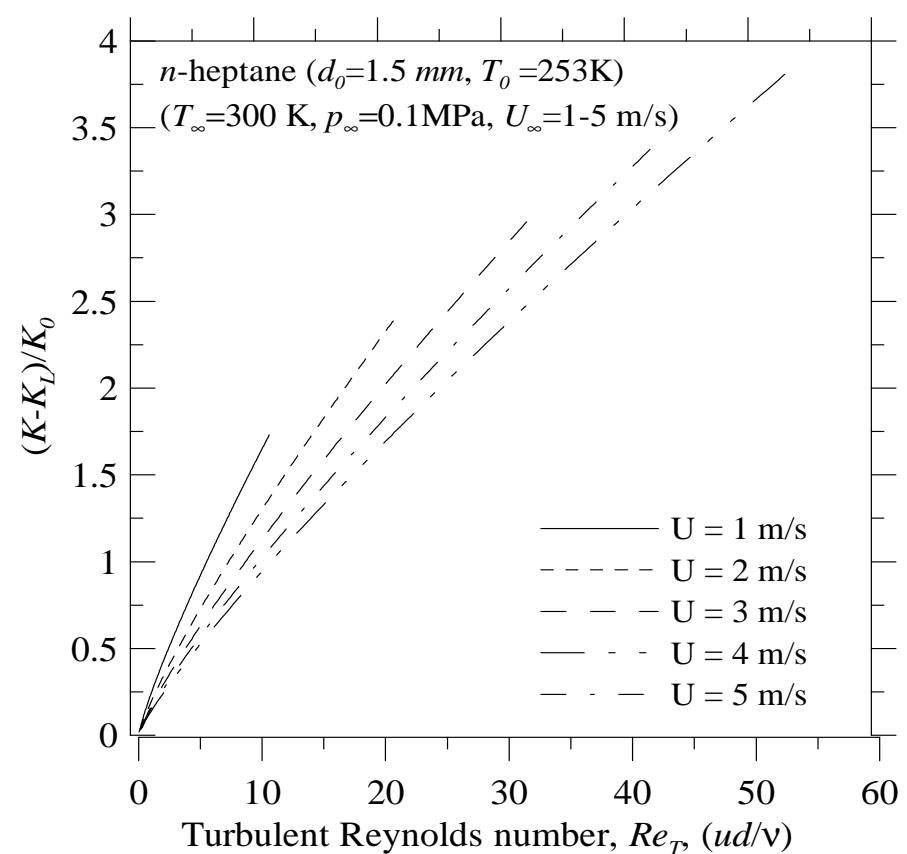

Figure 6 Effect of turbulence Reynolds number on vaporization of n-heptane at different mean velocities

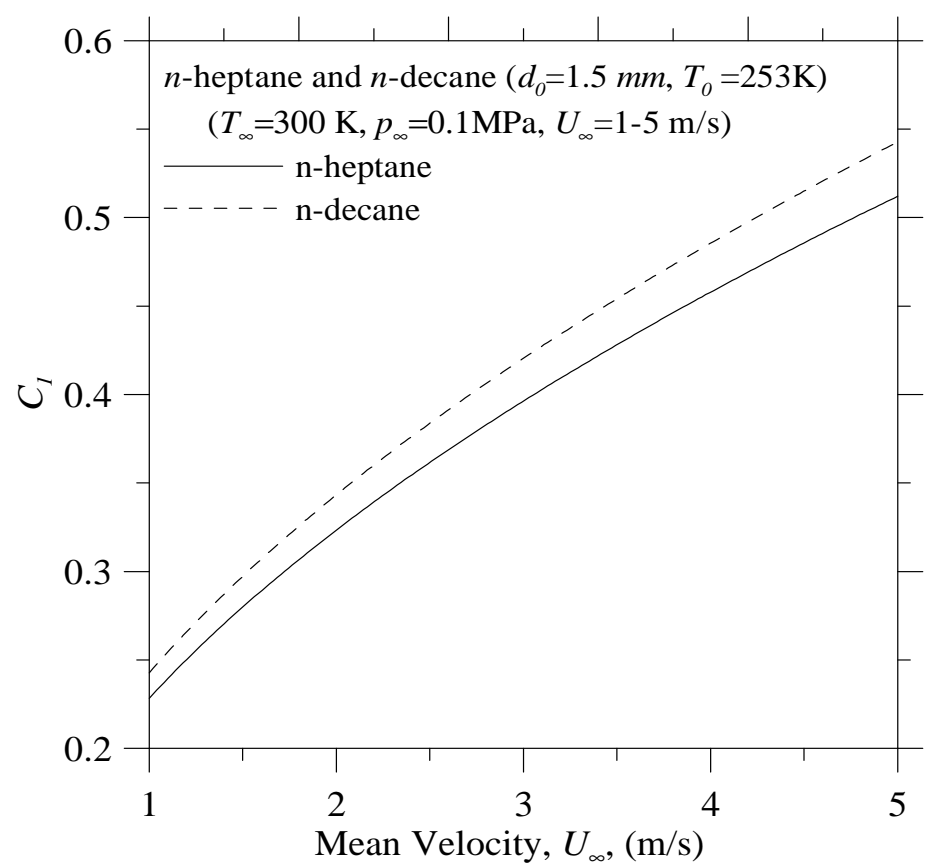

Figure 7 Variations of $\mathrm{C} 1$ with mean velocity for $\mathrm{n}$-heptane and n-decane droplets 


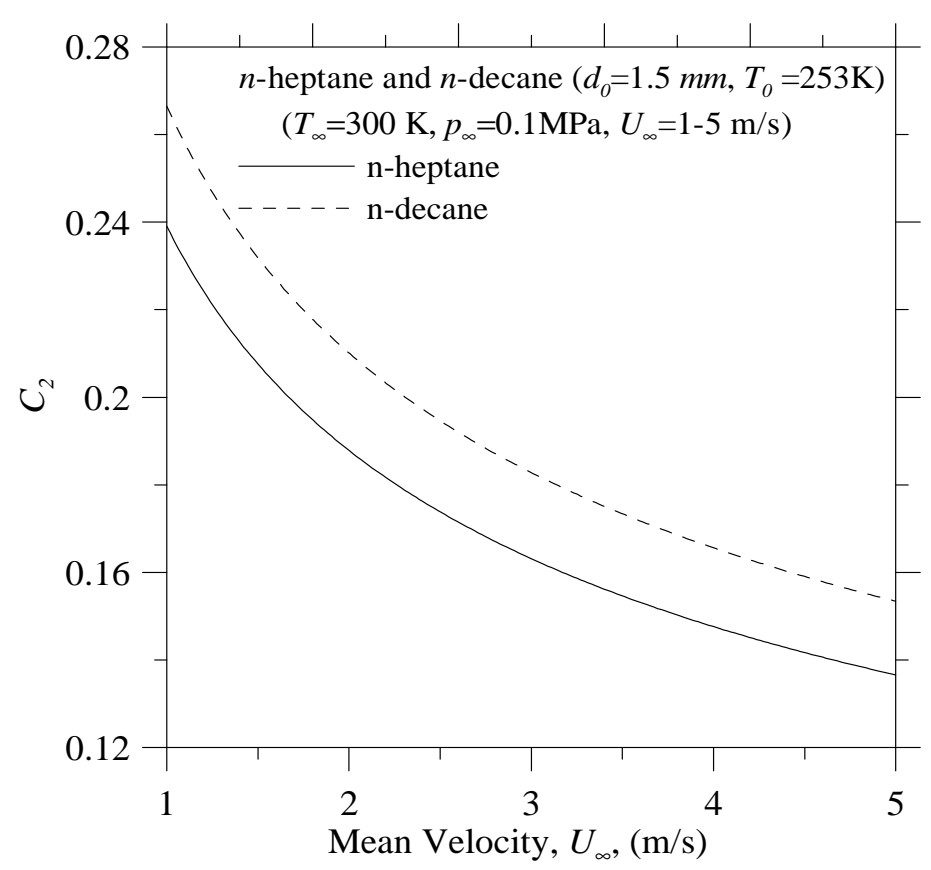

Figure 8 Variations of $\mathrm{C} 2$ with mean velocity for n-heptane and n-decane droplets

Gökalp et $a l$. [4] proposed an effective vaporization Damköhler number $D a_{v}$ to explain the influence of turbulence on droplet evaporation rate. The vaporization Damköhler number is defined as the ratio between the turbulence characterization time $\tau_{t}$ and evaporation characterization time $\tau_{v}$

$$
D a_{v}=\frac{\tau_{t}}{\tau_{v}}
$$

The turbulence characterization time and evaporation characterization time are defined as

$$
\begin{aligned}
& T_{t}=\frac{d^{2 / 3}}{\varepsilon^{1 / 3}}, \\
& T_{v}=\frac{\delta_{M}}{V_{r}},
\end{aligned}
$$

where $\varepsilon, \delta_{M}$, and $V_{r}$ are turbulence dissipation rate, vapor film thickness around the droplet and vapor blowing velocity, respectively. The turbulence dissipation rate is defined as [22]

$$
\varepsilon=\mathrm{A} \frac{u^{\prime 3}}{L_{e}},
$$

where A is a constant and assumed unity in this study [7] and $L_{e}$ is the integral length scale.

The vapor film thickness and vapor blowing velocity are defined according to film theory of Abramzon and Sirignano [23] as follows 


$$
\begin{gathered}
\delta_{M}=\frac{d}{S h_{0}-2} F\left(B_{M}\right), \\
V_{r}=\frac{D_{A B} S h^{*}\left(1+B_{M}\right)}{d},
\end{gathered}
$$

where $S h_{0}$ and $S h^{*}$ are the laminar and modified Sherwood number that are defined as

$$
\begin{aligned}
& S h_{0}=1+(1+\operatorname{Re} S c)^{0.7} \operatorname{Re}^{0.077}, \\
& S h^{*}=2+\frac{\left(S h_{0}-2\right)}{F\left(B_{M}\right)} .
\end{aligned}
$$

The diffusion correction factor $F\left(B_{M}\right)$ mentioned above is defined as

$$
F\left(B_{M}\right)=\left(1+B_{M}\right)^{0.7} \frac{\ln \left(1+B_{M}\right)}{B_{M}}
$$

The previous model (Eqs. (14-22)) was used to calculate the vaporization Damköhler number for $n$-heptane and $n$-decane at standard atmospheric pressure, room temperature, and different turbulence conditions. Figure 9 shows the predicted normalized turbulent vaporization rates of $n$-decane and $n$-heptane droplets versus the vaporization Damköhler number, $D a_{v}$, at room temperature conditions and the freestream conditions employed in this study. This figure displays also the experimental correlation of $\mathrm{Wu}$ et al. [7, 8]. It is important to mention that in this comparison the numerical data are obtained by employing a droplet Reynolds number value of 60 , freestream turbulence intensity in the range between 0 and $11 \%$, and a turbulent integral length scale assumed 5 times the initial droplet diameter to simulate the data of $\mathrm{Wu}$ et al. [7, 8]. As shown in this figure, the present data collapse on a single line having the following expression $K / K_{L}=0.9115 D a_{v}^{-0.1212}$. This best fit of the present data has a similar trend to the correlation proposed by Wu et al., which has the form $K / K_{L}=0.771 D a_{v}^{-0.111}$, but with slightly different proportionality coefficient and the power value for $D a_{v}$. This slight difference might be contributed to the experimental error as well as the assumption made for the turbulence integral length scale needed to calculate $D a_{v}$ and the heat and mass transfer correlations of Yearling [6] used in the evaporation model. Nevertheless, based on the results presented in this figure it is suggested that the vaporization Damköhler number can be used to correlate the effects of the freestream turbulence on the droplet evaporation rate at ambient room temperature

The effect of Reynolds number on the normalized evaporation rate-Damköhler number' correlation is studied by changing Reynolds number in the range from 60 to 500 that is achieved by changing the velocity from $0.6 \mathrm{~m} / \mathrm{s}$ to $5 \mathrm{~m} / \mathrm{s}$. It is found that Reynolds number has a negligible effect on this correlation especially for less volatile fuel (low Damköhler number) as clearly illustrated in Figure 10. 


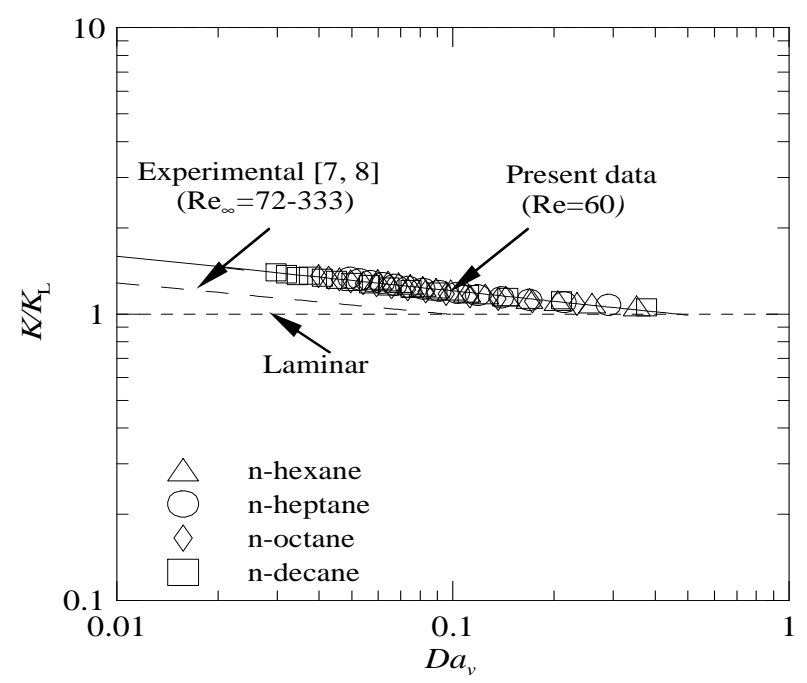

Figure 9 Comparison of present normalized evaporation rate versus Dav with $\mathrm{Wu}$ et al. $[7,8]$ data

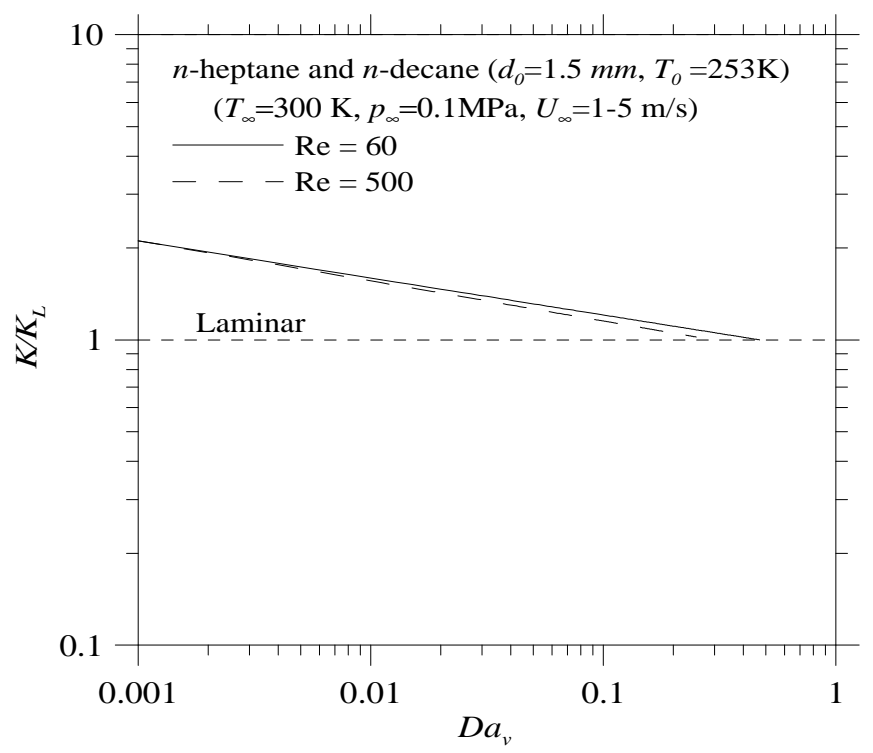

Figure 10 Normalized evaporation rate versus Damköhler number for low and high values of Reynolds number

\section{CONCLUSIONS}

A simplified semi-analytical analysis of the effects of turbulence on the vaporization of liquid fuel droplets subjected to forced convective flow conditions at room temperature and atmospheric pressure conditions was developed. The results of this model were over prediction compared with the only available published experimental data Although, the flow's turbulence intensity is moderate, up to $11 \%$, the model results 
show an enhancement effect of turbulence on the evaporation of liquid fuel droplets. Also, this model was used to predict a correlation between turbulent evaporation rate normalized by laminar evaporation and Damköhler number by a power relation. This correlation is extended to be applicable in a wide range of Reynolds numbers (60500).

\section{REFERENCES}

[1] Frössling, N., and Gerlands beitr, Geophys 52: 170-216 (1938).

[2] Ranz, W.E., and Marchall Jr., W.R., "Evaporation from drops", J. Chem. Eng. Prog. 48, pp. 173-180, 1952.

[3] Birouk, M., and Gökalp, I., "Current status of droplet evaporation in turbulent flows", Progress in Energy and combustion 4, pp.408-423, 2006.

[4] Gökalp, I., and Chauveau, C., "Mass transfer from liquid fuel droplets in turbulent flow", Combust. Flame 89, pp. 286-298, 1992.

[5] Hiromitsu, N., and Kawaguchi, O., "Influence of flow turbulence on the evaporation rate of suspended droplet in a hot air flow", Heat Transfer-Japanese Research 24, pp. 689-700, 1995.

[6] Yearling, P. R. A., Experimental determination of convective heat and mass transfer rates from single evaporating liquid droplets in a turbulent air flow, Ph.D. Thesis, NC University, Raleigh, NC. USA, 1995.

[7] $\mathrm{Wu}, \mathrm{J}-\mathrm{S}$., Lin, Y-J., and Sheen, H-J., "Effects of ambient turbulence and fuel properties on the evaporation rate of single droplets", Int. J. Heat Mass Transfer 44, pp. 4593-4603, 2001.

[8] Wu, J-S., Hsu, K-H., Kuo, P-M., and Sheen, H-J., "Evaporation model of a single hydrocarbon fuel droplet due to ambient turbulence at intermediate Reynolds number “, Int. J. Heat Mass Transfer 46, pp. 4741-4745, 2003.

[9] Ohta, Y., Shimoyama, K., and Ohigashi, S., "Vaporization and combustion of single liquid fuel droplets in turbulent environment “, Bulletin of JSME 18:47-56 (1975).

[10] Birouk, M., Chauveau, C., Sarh, B., Quilgars, A. and Gökalp, I., "Turbulence effects on the vaporization of monocomponent single droplets ", Combustion Science and Technology 113-114, pp. 413-428, 1996.

[11] Park, J-K., and Farrell, P.V., "Numerical study for free stream turbulence effects on a single droplet vaporization", SAE Technical Paper Series 901607:10p, 1990.

[12] Birouk, M. and Abou Al-Sood, M. M., "Droplet evaporation in a turbulent highpressure freestream- A numerical study", Int. J. of Thermal Science 49, pp. 264271, 2010.

[13] Birouk, M., Abou Al-Sood, M. M. and Gökalp, I., "Droplet evaporation in a turbulent environment at elevated pressure and temperature conditions", Combustion Science and Technology 180, pp. 1987-2014, 2008.

[14] Abou Al-Sood, M. M. and Birouk, M., "A Numerical model for calculating the vaporization rate of a fuel droplet exposed to a convective turbulent airflow“, Int. J. Num. Meth. Heat Fluid Flow 18, pp. 146-158, 2008.

[15] Abou Al-Sood, M. M., and Birouk, M., "Droplet heat and mass transfer in a turbulent airstream“, Int. J. Heat Mass Transfer 51, pp. 1313-1324, 2008. 
[16] Abou Al-Sood, M. M. and Birouk, M., "A numerical study of the effect of turbulence on mass transfer from a fuel droplet evaporating in hot freestream", Int. J. of Thermal Science 46, pp. 79-789, 2007.

[17] Kim, H., and Sung, N., "The effect of ambient pressure on the evaporation of a single droplet and a spray", Combust. Flame 135:261-270 (2003).

[18] Faeth, G.M., "Current status of droplet and liquid combustion", Prog. Energy. Combust. Sci. 3, pp. 191-224, 1977.

[19] Poling, B.E., Prausnitz, J.M., and O'Connell, J.P., The Properties of Gases and Liquids, McGraw- Hill, 5th Ed., 2000.

[20] Perry, R.H., Perry's Chemical Engineers' Handbook, McGraw-Hill, 7th Edition, 1997.

[21] Chen, J. S. and Lefebvre, A. H., "The role of Heat-up Period in Fuel Drop Evaporation“, Int. J. Turbo and Jet Engines 2, pp. 315-325, 1985.

[22] Hinze, J. O., Turbulence, McGraw Hill, $1^{\text {st }}$ edition, 1959.

[23] Abramzon, B. and Sirignano, W. A., "Droplet vaporization model for spray combustion calculations", Int. J. Heat Mass Transfer 3:1605-1618 (1989).

\section{نموذج مبسط لتأثير الإضطراب على قطرات سائل أحاديه فى حالة الحمل الحرارى القسرى}

هذه الورقة تمثل دراسة| نصف تحليلية لنمذجة تأثثر السريان المعتدل الاضطراب على تبخير قطرات من الوقود معزولة في درجة حرارة الغرفة المحيطة وظروف الضغط الجوي مستخدمة علاقات تجريبية بحتة بين أرقام نسلت و شيروود المضطربة (Nu, Sh). تم اختبار نوعين من الوقود الهيدروكربوني وهما: هيبتان و ديكان و ييلغ القطر الإبتدائى لكل قطرة 1.5 ملم. وتم تغيير قيمة عدد رينولدز في لي

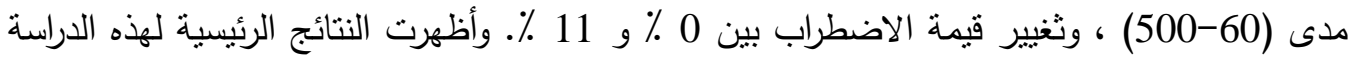

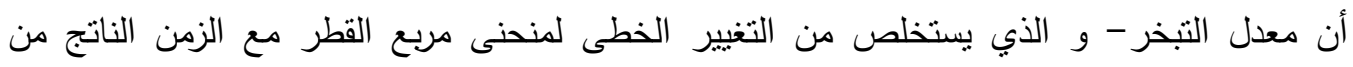

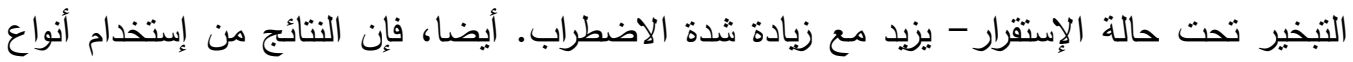

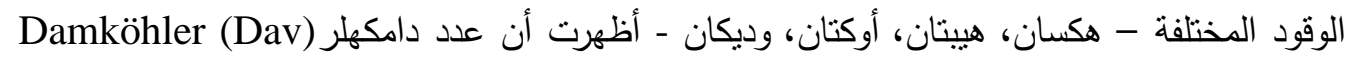

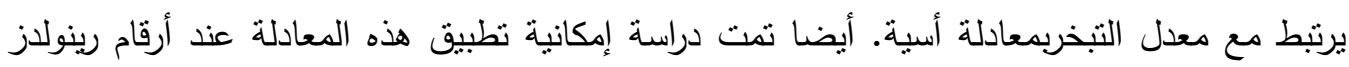
العالية فى المدى المستخدم بالدراسة. 